\title{
The Mechanism of Action of Ethoxidol on Oxidative Stress Indices in Heart Failure and Hypotension
}

\author{
DOI: $10.17691 / \mathrm{stm} 2020.12 .2 .08$
}

Received October 22, 2019

V.G. Kukes, MD, DSc, Academician of the Russian Academy of Sciences, Professor,

Department of Clinical Pharmacology and Propedeutics of Internal Diseases ${ }^{1}$;

Head of the Scientific Direction "Pharmacology"2;

O.K. Parfenova, Student, A.P. Nelyubin Institute of Pharmacy';

B.K. Romanov, MD, DSc, Deputy Director General on Scientific Work2;

A.B. Prokofiev, MD, DSc, Professor, Department of Clinical Pharmacology and Propedeutics of Internal Diseases ${ }^{1}$; Director of the Clinical Pharmacology Center2;

E.V. Parfenova, MD, DSc, Professor, Corresponding Member of the Russian Academy of Sciences, Deputy Director General ${ }^{3}$; Director of the Institute of Experimental Cardiology3;

N.G. Sidorov, Student, A.P. Nelyubin Institute of Pharmacy';

A.A. Gazdanova, MD, PhD, Associate Professor, Department of Clinical Pharmacology and Propedeutics of Internal Diseases ${ }^{1}$;

L.I. Pavlova, MD, PhD, Associate Professor, Department of Clinical Pharmacology and Propedeutics of Internal Diseases ${ }^{1}$;

V.I. Zozina, PhD Student, Department of Clinical Pharmacology and Propedeutics of Internal Diseases ${ }^{1}$;

A.D. Andreev, Student, Medical Faculty';

T.V. Aleksandrova, Senior Analyst';

S.V. Chernova, PhD, Associate Professor, Department of Pharmaceutical and Toxicological Chemistry named after A.P. Arzamastsev';

G.V. Ramenskaya, DSc, Director, A.P. Nelyubin Institute of Pharmacy'; Head of the Department of Pharmaceutical and Toxicological Chemistry named after A.P. Arzamastsev ${ }^{1}$

${ }^{1}$ I.M. Sechenov First Moscow State Medical University (Sechenov University), 8/2 Malaya Trubetskaya St., Moscow, 119991, Russia;

${ }^{2}$ Scientific Centre for Expert Evaluation of Medicinal Products of the Ministry of Health

of the Russian Federation, 8, Bld. 2, Petrovsky Boulevard, Moscow, 127051, Russia;

${ }^{3}$ National Medical Research Center of Cardiology of the Ministry of Health of the Russian Federation,

$15 \mathrm{~A} 3^{\text {rd }}$ Cherepkovskaya St., Moscow, 121552, Russia

The aim of the investigation was to study the effect of 2-ethyl-6-methyl-3-hydroxypyridine malate (Ethoxidol) on the concentration of oxidative stress metabolites in patients with chronic heart failure (CHF) and hypertension.

Materials and Methods. 126 patients with FC I-III CHF have been examined. In addition to their individual therapy these patients received intravenous infusions of Ethoxidol. Blood content of 2,3-diphosphoglycerate (2,3-DPG), oxygen tension $\left(\mathrm{pO}_{2}\right)$, $\mathrm{pH}, \mathrm{concentration}^{-}$ of total peroxides, lactate, and aldosterone were identified. 2,3-DPG levels ( $\mathrm{g} / \mathrm{L}$ erythrocytes) in whole blood samples were determined by an enzyme assay using the reagent kit (Rosh, Germany), values of $\mathrm{pO}_{2}, \mathrm{pCO}_{2}, \mathrm{pH}$, lactate in the venous blood were measured using gas analyzer Stat Profil pHOx Ultra (Nova Biomedical, USA). Indices of oxidative stress, i.e. the concentration of plasma total peroxides, were investigated by ELISA using OxyStat kit (Biomedica, Austria). Peripheral venous blood samples were collected from all patients before and 6 days after the daily intravenous Ethoxidol infusion.

Results. In patients with FC I, II, III CHF, on day 7 after intravenous Ethoxidol infusion at a dose of $100 \mathrm{mg} /$ day, statistically significant growth $\left(\mathrm{p}=0.0002\right.$ ) of $\mathrm{PaO}_{2}$ level by $15.7,17.4$, and $22.8 \%$, respectively, was noted. In patients with $\mathrm{FC} \mathrm{I}$, II, III CHF in the group receiving standard therapy, statistically significant $(p=0.002)$ reduction of 2,3-DPG level by $2.7,2.4$, and $4.0 \%$, respectively, was registered. On day 7 after the infusion of Ethoxidol at a dose of $100 \mathrm{mg} /$ day, its decrease by $5.7,10.5$, and $26.2 \%$, respectively ( $p<0.0001)$, was also observed.

Corresponding author: Vladimir G. Kukes, e-mail: elmed@yandex.ru 


\section{CLINICAL SUPPLEMENTS}

Conclusion. The increased concentrations of active oxygen forms have been established to negatively affect various bodily functions and adversely influence the pathophysiology of numerous diseases. Application of antioxidants, including Ethoxidol presented by us in this article, may become a clue to the development of preventive measures for many serious diseases.

Key words: active forms of oxygen; antioxidants; heart failure; hypertension; telomeres.

\section{Introduction}

Redox reactions underlying the metabolic processes in the human body result in the formation of peroxide compounds. In recent time, the effect of the active forms of oxygen (AFO) on the pathophysiology of numerous diseases is being studied and this interest is determined not only by their direct toxicity but the alteration of signal pathways which regulate functions of the cells and organs.

Organic peroxides are the first products of reactions taking place between the cell components and AFO. There is a direct relation between the presence of AFO $\left(\mathrm{O} \dot{2}, \mathrm{H}_{2} \mathrm{O}_{2}\right)$ and the circulating biological peroxides. Active forms of oxygen are the necessary components of vital activity of the cells and the organism as a whole. They participate in many metabolic and regulatory processes. All these processes can be implemented only if the physiological level of AFO is maintained due to the functioning of antioxidant systems. For example, coenzyme Q10 takes part in the antioxidant protection of the organism [1-4]. Impairment in the work of the ubiquinone results in destabilization of the electron transport chain (ETC) that is one of the causes of myocardial contractility reduction. Antioxidants can also transport electrons and this contributes to normalization of the ETC work and improvement of myocardial contractility.

Oxidative stress is associated with free radicals and decreases the activity of enzymes and substances including 2,3-diphosphoglycerate (2,3-DPG). This secondary messenger located in erythrocytes influences their main function: oxygen transport. Changes in the 2,3-DPG content alter hemoglobin affinity to oxygen: accelerate dissociation of oxyhemoglobin into hemoglobin and oxygen. When 2,3-DPG content is reduced, oxygen tension $\left(\mathrm{pO}_{2}\right)$ in the blood decreases. 2,3-DPG is completely blocked by $\mathrm{H}_{2} \mathrm{O}_{2}$ [5-7]. In 2000, the authors [5] proved that if $\mathrm{H}_{2} \mathrm{O}_{2}$ is added, 2,3-DPG synthesis decreases, and in the works [6-8] it has been established to be blocked completely.

In hypoxia, the concentration of acidic products (lactate, active oxygen) is increased which causes the reduction of the activity of cytochrome P450 isoenzymes, for example, isoenzyme CYP $3 A 4$, and this worsens the course of heart failure. CYP $3 A 4$ is involved in the aldosterone metabolism, therefore, its activation increases the level of aldosterone metabolism [9] promoting the reduction of concentration and normalization of water-electrolyte metabolism [10].
Currently, a second-generation antioxidant, a lowtoxic medical preparation 2-ethyl-6-methyl-3-hydroxypyridine malate (Ethoxidol), was registered in the Russian Federation. It causes antihypoxic effect in ischemic conditions developing during diabetes mellitus (a registered indication). The drug was synthetized and studied in 1993 by L.N. Sernov.

It has been established that in 10-month-old white rats with experimentally induced myocardial ischemia, Ethoxidol increased the enzymatic activity of the cellular antioxidant system, superoxide dismutase, and catalase, decreased the intensity of the oxidative stress, reduced the amount of lipid peroxidation products, diene conjugate, and malondialdehyde. All this is accompanied by the signs of cardiomyocyte membrane stabilization, decrease of the tissue hypoxia extent, and rise in the ATP content in the myocardial homogenate.

Based on the positive results of the preclinical investigations, a post-registration clinical assessment of the efficacy and safety of Ethoxidol extending its indications has been carried out [8].

The aim of the investigation was to study the mechanism of action of 2-ethyl-6-methyl-3hydroxypyridine malate (Ethoxidol) on the concentration of oxidative stress metabolites in patients with chronic heart failure (CHF) and hypertension.

\section{Materials and Methods}

126 patients with CHF, I-III functional class (FC), participated in the study. They received intravenous infusions of Ethoxidol additionally to their individual therapy. The study complied with the Declaration of Helsinki (2013) and was approved by the Ethical Committee of I.M. Sechenov First Moscow State Medical University. Written informed consent was obtained from every patient.

Blood content of 2,3-DPG, $\mathrm{pO}_{2}, \mathrm{pH}$, concentration of total peroxides, lactate, and aldosterone were identified. 2,3 DPG levels (g/L erythrocytes) in whole blood samples were determined by an enzyme assay using the reagent kit (Rosh, Germany), values of $\mathrm{pO}_{2}, \mathrm{pCO}_{2}, \mathrm{pH}$, lactate in the venous blood were measured using gas analyzer Stat Profil pHOx Ultra (Nova Biomedical, USA). Indices of oxidative stress, i.e. the concentration of plasma total peroxides, were investigated by ELISA using OxyStat kit (Biomedica, Austria). Peripheral venous blood samples were collected from all patients before and 6 days after the daily intravenous Ethoxidol infusion. 
Statistical data processing. The results were analyzed using IBM SPSS Statistics 20.0 program. To describe the values presented in the quantitative variables at the assumed normal distribution of the general population, parametric methods of descriptive statistics were used: sample average \pm standard deviation $(x \pm \sigma)$. Differences were considered significant at $p<0.05$.

\section{Results}

In patients with $\mathrm{FC} \mathrm{I}$, II, III CHF, a statistically significant growth $(p=0.0002)$ of $\mathrm{PaO}_{2}$ level by 15.7 , 17.4 , and $22.8 \%$, respectively, was noted at day 7 after intravenous Ethoxidol infusion at a dose of $100 \mathrm{mg} /$ day (see the Table). When assessing the efficacy of the standard therapy (before Ethoxidol infusion) in the patients with FC I, II, III CHF, statistically significant $(p=0.002)$ reduction of $2,3-D P G$ level by $2.7,2.4$, and $4.0 \%$, respectively, was registered. On day 7 after the infusion of Ethoxidol at a dose of $100 \mathrm{mg} / \mathrm{day}$, a more considerable statistically significant $(p<0.0001)$ decrease by $5.7,10.5$, and $26.2 \%$, respectively, was observed.

\section{Discussion}

The obtained data allow us to suppose that Ethoxidol action depends on the feedback mechanism of the oxidase systems, that is on the increase of the superoxide dismutase (SOD) activity. It may be connected with the increase of $\mathrm{O} \dot{2}$ production which subsequently reduces the concentration of organic peroxides [11].

Sousa et al. [12] have studied the pathogenesis of hypertension. Since angiotensin II (Ang II) is the main hormone rising blood pressure, they injected it to the rats in order to determine the ways of hypertension development. This hormone causes the efferent arterioles to constrict and, consequently, there occurs the reduction of hydrostatic and increase of oncotic pressure in peritubular capillaries - both of these effects result in the increase of water and sodium reabsorption. To evaluate the effect of the treatment, catalasepolyethylene glycol (PEG-catalase) was injected to the rats.

Expression of $\mathrm{H}_{2} \mathrm{O}_{2}$ was increased with Ang II injection. The $\mathrm{H}_{2} \mathrm{O}_{2}$ level was higher in blood plasma and urine, however, Ang II caused a double effect on the angiotensinogen level: it became higher in urine but lower in plasma. Besides, Ang II
Dynamics of indices in patients

with chronic heart failure before and after treatment with Ethoxidol $(x \pm \sigma)$

\begin{tabular}{lcc}
\hline \multicolumn{1}{|c}{ Indices } & $\begin{array}{c}\text { Standard } \\
\text { therapy }\end{array}$ & $\begin{array}{c}\text { After treatment } \\
\text { with Ethoxidol }\end{array}$ \\
\hline $\mathrm{pO}_{2}(\mathrm{~mm} \mathrm{Hg})$ & $39.26 \pm 16.80$ & $59.96 \pm 23.27$ \\
\hline 2,3-DPG $(\mathrm{g} / \mathrm{L})$ : & $0.51 \pm 0.04$ & $0.43 \pm 0.04$ \\
$\mathrm{FC} \mathrm{I}, \mathrm{II}$ & $0.23 \pm 0.02$ & $0.32 \pm 0.02$ \\
\hline $\mathrm{FC} \mathrm{III}$ & $51.60 \pm 5.88$ & $53.40 \pm 5.45$ \\
\hline EchoCG, ejection fraction (\%) & & \\
\hline Total concentration & $1220 \pm 250$ & $1050 \pm 210$ \\
of organic peroxides $(\mu \mathrm{mol} / \mathrm{L})$ & $7.41 \pm 0.04$ & $7.39 \pm 0.04$ \\
\hline pH & $2.23 \pm 0.64$ & $1.91 \pm 0.76$ \\
\hline Lactate $(\mathrm{mmol} / \mathrm{L})$ & $490.0 \pm 188.40$ & $1020.0 \pm 178.80$ \\
\hline Diuresis volume $(\mathrm{ml})$ & & \\
\hline
\end{tabular}

raised the $\mathrm{H}_{2} \mathrm{O}_{2}$ level in the renal medulla layer whereas PEG-catalase reduced it (Figure 1).

In the rats with hypertension, the rise of $\mathrm{H}_{2} \mathrm{O}_{2}$ systemic level has been established in urine as well which causes narrowing of the vessels and pressure elevation.

The elevation of the $\mathrm{H}_{2} \mathrm{O}_{2}$ level increases Ang II synthesis in kidneys which contributes to the activation of renin-angiotensin system and, consequently, to the

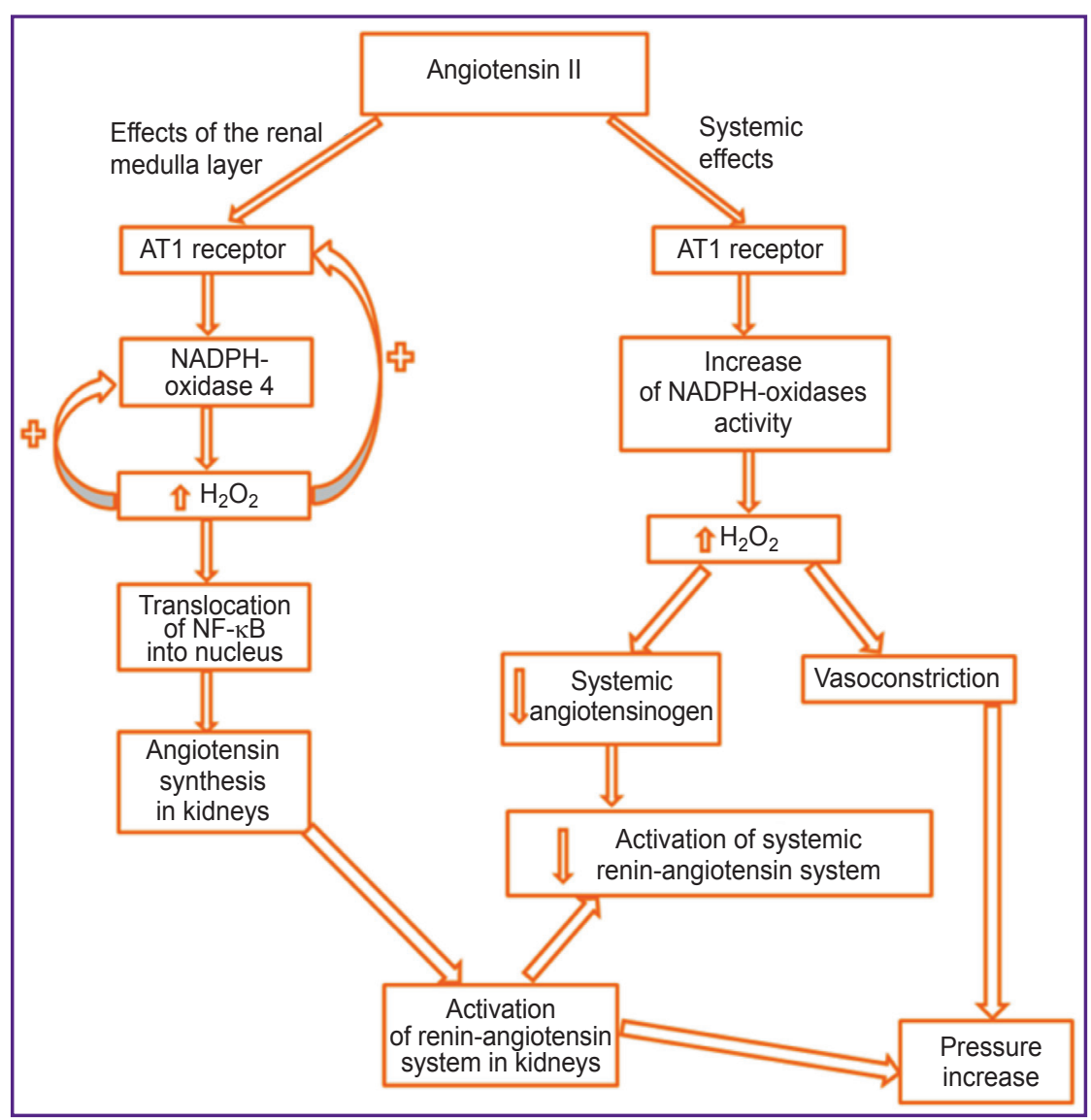

Figure 1. Mechanisms involved in the elevation of arterial pressure and activation of renin-angiotensin system by means of Ang II and $\mathrm{H}_{2} \mathrm{O}_{2}$ [12] 
pressure elevation. PEG-catalase produced only a shorttime effect despite a steady reduction of $\mathrm{H}_{2} \mathrm{O}_{2}$ level [12]. Though arterial pressure was noticeably reduced during the first days of PEG-catalase injection, this effect was not observed at the end of the treatment, which signified the necessity of antioxidant application.

Münzel et al. [13] have considered the molecular basis of the oxidative stress in heart failure. It is characterized by the activation of the sympathetic nervous and reninangiotensin-aldosterone systems. This neuroendocrine activation is connected with the oxidative stress in the myocardium and vascular network. In patients with heart failure, oxidative stress occurs in the myocardium and blood plasma and correlates with left ventricle dysfunction. AFO affect negatively calcium transfer in the myocardium $\left(\mathrm{Ca}^{2+}\right)$ that causes arrhythmia and promotes heart remodeling inducing a hypertrophic signal transmission, apoptosis, and necrosis. Enzymatic sources for AFO such as NADPH-oxidases (NOX), unbound nitric oxide (NO), and mitochondria are considered the sources of AFO in heart failure causing dysfunction of the vessels and myocardium. It is important that mitochondria enhance the synthesis of AFO originating from NOX and can in this way function as redox centers in the physiology of the heart and in its illness [13].

In myocytic mitochondria, $\mathrm{O}_{2}$ is generated by the ETC, but is quickly changed into $\mathrm{H}_{2} \mathrm{O}_{2}$ by manganesedependent SOD. $\mathrm{H}_{2} \mathrm{O}_{2}$ is then eliminated by the antioxidant enzymes (glutathione peroxidase and peroxiredoxin) which generate NADPH [13]. In mitochondria, the Krebs cycle generates $\mathrm{NADH}$ which yields electrons to ETC for ATP production. Nevertheless, the Krebs cycle also produces substrates restoring $\mathrm{NADPH}$, which, in its turn, regenerates antioxidant enzymes. In heart failure, defects in the location of cytosolic $\mathrm{Ca}^{2+}$ and $\mathrm{Na}^{+}$in cardiac myocytes (e.g. decrease in the release of sarcoplasmic reticulum $\mathrm{Ca}^{2+}$ and elevation of $\mathrm{Na}^{+}$) diminish the accumulation of mitochondrial $\mathrm{Ca}^{2+}$ and thereby prevent regeneration of $\mathrm{NADH}$ and NADPH interrupting the ATP production by provoking AFO ejection from mitochondria $[13,14]$.

In heart failure, the limited substrates for ATP production (i.e. $\mathrm{NADH}$ ) and $\mathrm{AFO}$ elimination (i.e. NADPH) face the demand in energy caused by a high cardiac preload, afterload, and heart rate. In heart failure, the increased AFO production and reduction in their elimination in the cardiac myocytes promote the increase of pure ejection of mitochondrial AFO which play the main role in the pathogenesis of heart failure (decrease of antioxidant enzyme concentrations) [13].

Active forms of oxygen regulate numerous cellular functions including growth and proliferation of endothelial and smooth muscle cells. However, extreme levels of oxidants mediate vascular diseases via direct and irreversible damage of macromolecules and growth of the redox potential in the vascular walls as well $[13,14]$.

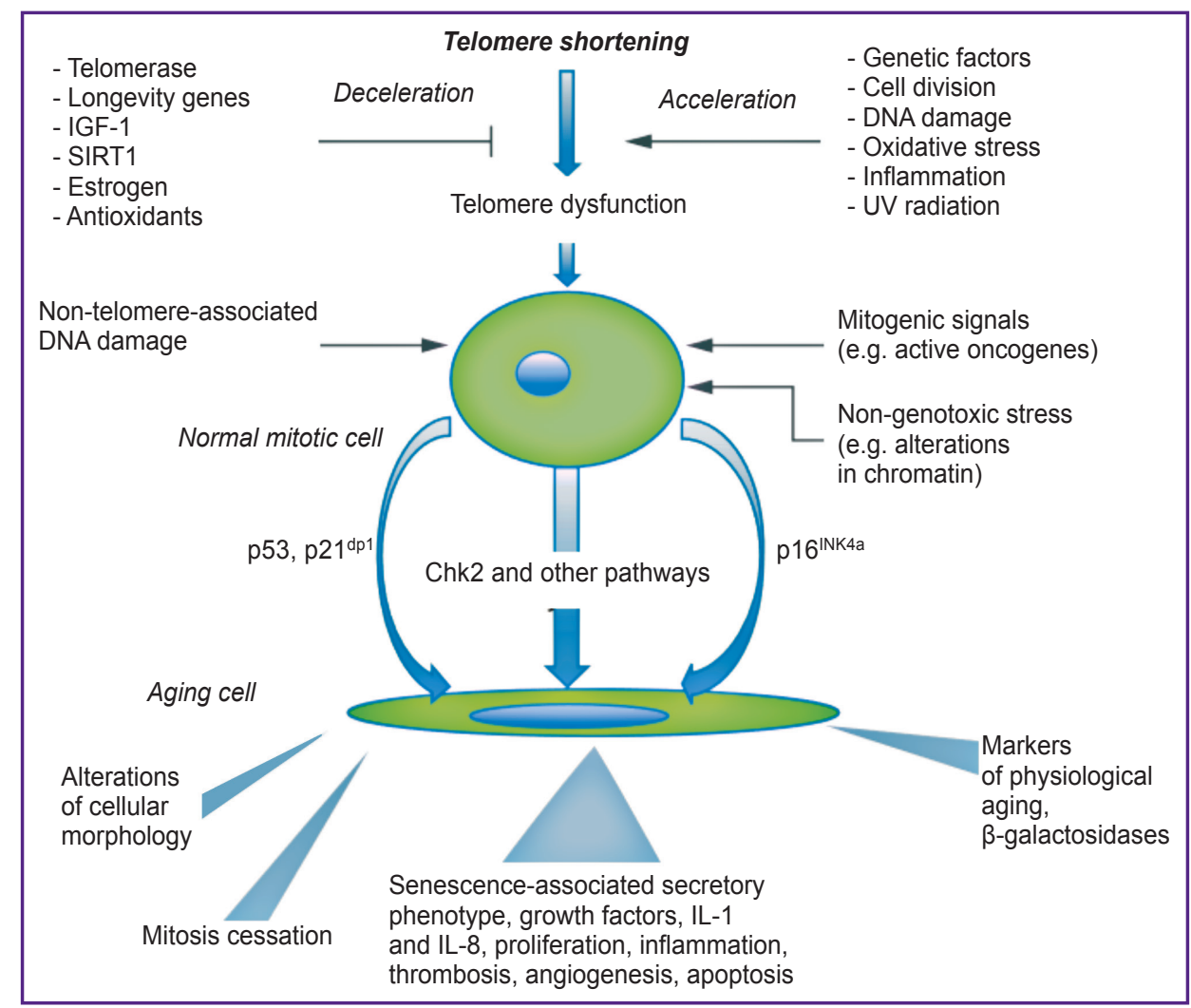

Figure 2. Factors influencing the telomere length [15] 


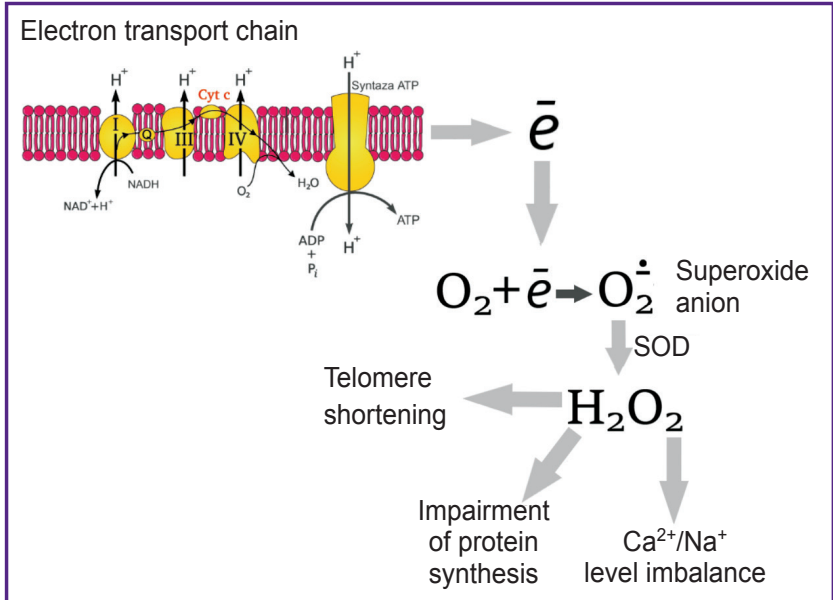

Figure 3. Negative $\mathrm{H}_{2} \mathrm{O}_{2}$ manifestations

In the vascular network, $\mathrm{O}_{2}$ is generated by NADPHoxidase, xanthine oxidase, and mitochondria. $\mathrm{SOD}$ converts $\mathrm{O}_{2}$ into $\mathrm{H}_{2} \mathrm{O}_{2}$. Due to the Fenton reaction, $\mathrm{H}_{2} \mathrm{O}_{2}$ can spontaneously change into a hydroxyl radical $\mathrm{OH}$. Being highly reactive $\mathrm{OH}$ can damage the majority of cellular compartments [13].

Formation of $\mathrm{AFO}$ and oxidative stress mediate injury of tissues and cells, which may turn into an inflammation cycle. Investigations have shown that AFO may accelerate telomere shortening and damage the DNA, and thereby induce aging. Oxidants cause telomere attrition in the cultured human endothelial cells whereas antioxidants prevent their shortening. Aging, in its turn, results in further AFO generation. Telomere dysfunction and vascular aging are associated with the increased generation of AFO, molecules of adhesion and inflammation, and also beta-galactosidase. Cell division and telomere DNA damage are the main factors leading to telomere shortening and dysfunction. The oxidative stress and inflammation promote strongly telomere attrition resulting in cell aging. And vice versa, in the vicious circle, cellular aging induces inflammation and formation of oxidative radicals [15] (Figure 2).

Thus, a negative effect of AFO causes progression of heart failure, therefore, the application of antioxidants directed to the blockage and inactivation of their action is quite reasonable. In the mentioned Russian and foreign investigations, an important role of these forms in the cellular metabolism is noted, but at the same time, a negative effect of the increased AFO concentration, especially that of $\mathrm{H}_{2} \mathrm{O}_{2}$, on various body functions is indicated as well as a negative influence on the pathophysiology of numerous diseases (Figure 3).

\section{Conclusion}

The increased concentrations of active forms of oxygen have been established to negatively affect various bodily functions and adversely influence the pathophysiology of numerous diseases. Application of antioxidants, including Ethoxidol presented by us in this article, may become a clue to the development of preventive measures for many serious diseases.

Research funding. The work was not supported by any financial sources.

Conflicts of interest. The authors have no conflicts of interest to declare.

\section{References}

1. Martinucci S., Szabò I., Tombola F., Zoratti M. $\mathrm{Ca}^{2+}$ reversible inhibition of the mitochondrial megachannel by ubiquinone analogues. FEBS Lett 2000; 480(2-3): 89-94, https://doi.org/10.1016/s0014-5793(00)01911-6.

2. Choksi K.B., Boylston W.H., Rabek J.P., Widger W.R., Papaconstantinou J. Oxidatively damaged proteins of heart mitochondrial electron transport complexes. Biochim Biophys Acta 2004; 1688(2): 95-101, https://doi.org/10.1016/j. bbadis.2003.11.007.

3. Littarru G.P., Langsjoen P. Coenzyme Q10 and statins: biochemical and clinical implications. Mitochondrion 2007; Suppl: S168-S174, https://doi.org/10.1016/j.mito.2007. 03.002 .

4. Siciliano G., Volpi L., Piazza S., Ricci G., Mancuso M., Murri L. Functional diagnostics in mitochondrial diseases. Biosci Rep 2007; 27(1-3): 53-67, https://doi.org/10.1007/ s10540-007-9037-0.

5. Fokina K.V., Yazykova M.Y., Danshina P.V., Schmalhausen E.V., Muronetz V.I. Participation of glyceraldehyde-3-phosphate dehydrogenase in the regulation of 2,3-diphosphoglycerate level in erythrocytes. Biochemistry (Mosc) 2000; 65(4): 463-468.

6. Drapkina O.M., Palatkina L.O. Markers of cytokine activation and oxidative stress in patients with chronic heart failure. Serdechnaya nedostatochnost' 2013; 14(6): 341-346.

7. Romanov B.K. Regulation of myocardial lysosomal enzyme activity by calcium. Biomeditsinskaya khimiya 2005; 51(6): 634-642.

8. Kukes V.G. Itogi issledovaniya otechestvennogo preparata, antioksidanta II pokoleniya ehtoksidola [The results of a study of a domestic drug, an antioxidant of the second generation of ethoxidol]. Moscow: ANO "MAKFiF"; 2017.

9. Kukes V.G., Prokof'ev A.B., Checha O.A., Goroshko O.A., Smirnov V.V., Krasnykh L.M., Vasilenko G.F., Otdelenov V.A., Temnaja I.S., Mjasnikov D.G., Pshenichnikov V.G., Grigor'ev M.I. Method for activating P450CYP3A4 isoenzyme in patients with chronic cardiac failure. Patent RU 2554775. 2014.

10. Palatkina L.O., Korneeva L.O., Drapkina O.M. Oxidative stress, its role in the pathogenesis of chronic heart failure, and potential methods of correction. Kardiovaskulyarnaya terapiya $i$ profilaktika 2012; 11(6): 91-94.

11. Goroshko O.A., Novikov K.N., Kukes V.G., Voeikov V.L., Arkhipov V.V., Buravleva E.V., Berdnikova N.G., Zhestovskaya A.S. Correction of oxidative stress in patients with chronic cerebral ischemia. Klinicheskaya meditsina 2016; 94(7): 549-553.

12. Sousa T., Oliveira S., Afonso J., Morato M., Patinha D., Fraga S., Carvalho F., Albino-Teixeira A. Role of $\mathrm{H}(2) \mathrm{O}(2)$ in hypertension, renin-angiotensin system activation and renal 


\section{CLINICAL SUPPLEMENTS}

medullary disfunction caused by angiotensin II. Br J Pharmacol 2012; 166(8): 2386-2401, https://doi.org/10.1111/j.1476-5381. 2012.01957.x.

13. Münzel T., Camici G.G., Maack C., Bonetti N.R., Fuster V., Kovacic J.C. Impact of oxidative stress on the heart and vasculature: part 2 of a 3-part series. J Am Coll Cardiol 2017; 70(2): 212-229, https://doi.org/10.1016/j.jacc. 2017.05.035.

14. Yamamoto S., Tsutsui H., Tagawa H., Saito K.,
Takahashi M., Tada H., Yamamoto M., Katoh M., Egashira K., Takeshita A. Role of myocyte nitric oxide in $\beta$-adrenergic hyporesponsiveness in heart failure. Circulation 1997; 95(5): 1111-1114, https://doi.org/10.1161/01.cir.95.5.1111.

15. Sack M.N., Fyhrquist F.Y., Saijonmaa O.J., Fuster V., Kovacic J.C. Basic biology of oxidative stress and the cardiovascular system: part 1 of a 3-part series. J Am Coll Cardiol 2017; 70(2): 196-211, https://doi.org/10.1016/j. jacc.2017.05.034. 